\title{
The Effect of Delivery Method on the Pharmacokinetic Properties of Meloxicam in Pre-Weaned Dairy Calves with Diarrhea
}

\author{
Daniel Shock $^{1}$, Steven Roche ${ }^{1 *}{ }^{(\mathbb{C}}$, Denis Nagel ${ }^{2}$, Merle Olson ${ }^{2}$ \\ ${ }^{1}$ ACER Consulting, Guelph, Canada \\ ${ }^{2}$ Alberta Veterinary Labs/Solvet Inc., Calgary, Canada \\ Email: *sroche@acerconsult.ca
}

How to cite this paper: Shock, D., Roche, S., Nagel, D. and Olson, M. (2020) The Effect of Delivery Method on the Pharmacokinetic Properties of Meloxicam in Pre-Weaned Dairy Calves with Diarrhea. Open Journal of Veterinary Medicine, 10, 27-38. https://doi.org/10.4236/ojvm.2020.103003

Received: December 29, 2019

Accepted: February 25, 2020

Published: February 28, 2020

Copyright $\odot 2020$ by author(s) and Scientific Research Publishing Inc. This work is licensed under the Creative Commons Attribution International License (CC BY 4.0).

http://creativecommons.org/licenses/by/4.0/

\begin{abstract}
The non-steroidal anti-inflammatory drug meloxicam is commonly used as adjunct therapy for neonatal calf diarrhea to control pain and inflammation. The objective of this study was to compare the pharmacokinetics of meloxicam in diarrheic pre-ruminant dairy calves dosed either orally or subcutaneously. Twelve pre-ruminant male dairy calves with mild to moderate diarrhea were randomly assigned to receive one of four treatments (three per group): subcutaneous meloxicam (SM, $0.5 \mathrm{mg} / \mathrm{kg}$ body weight); an oral bolus meloxicam suspension (OM, $1 \mathrm{mg} / \mathrm{kg}$ body weight); an oral meloxicam suspension added to a feeding of oral electrolytes (EM, $1 \mathrm{mg} / \mathrm{kg}$ body weight); and an oral meloxicam suspension added to a feeding of milk replacer (MM, $1 \mathrm{mg} / \mathrm{kg}$ body weight). The predicted pharmacokinetic parameters for OM, MM, EM, and SM groups were: half-life ( $56.8 \pm 21.7$ vs. $136.0 \pm 26.6$ vs. 85.2 \pm 21.7 vs. $36.3 \pm 21.7 \mathrm{~h}), \mathrm{C} \max (4.3 \pm 0.4$ vs. $3.7 \pm 0.4$ vs. $3.9 \pm 0.4$ vs. $2.1 \pm 0.4$ $\mu \mathrm{g} / \mathrm{mL}), \operatorname{Tmax}(13.3 \pm 4.0$ vs. $10.7 \pm 4.0$ vs. $13.3 \pm 4.0$ vs. $2.7 \pm 4.0 \mathrm{~h})$, and $\mathrm{AUC}_{0-\infty}(383.4 \pm 126.8$ vs. $877.8 \pm 155.3$ vs. $457.1 \pm 126.8$ vs. $126.4 \pm 126.8 \mathrm{~h}$ * $\mu \mathrm{g} / \mathrm{mL}$ ). Oral meloxicam, especially MM, had extended elimination phases relative to SM. All meloxicam therapies provided effective therapeutic levels but all oral therapies $(1 \mathrm{mg} / \mathrm{kg})$ provided longer durations of activity than injectable meloxicam $(0.5 \mathrm{mg} / \mathrm{kg})$.
\end{abstract}

\section{Keywords}

Meloxicam, Dairy Calves, Pharmacokinetics, Diarrhea, Anti-Inflammatory

\section{Introduction}

Diarrhea is one of the most prevalent disease challenges facing dairy calves, af- 
fecting $21 \%$ of animals and accounting for $56 \%$ of all deaths in the preweaning period [1]. The major pathogens responsible for diarrhea in pre-weaned dairy calves are rotavirus, coronavirus, E. coli, Salmonella, Clostridium perfringens, and Cryptosporidium parvum [2]. Some pathogens, such as E. coli, trigger enterocytes to secrete fluids into the intestine, while others (i.e. rotavirus, coronavirus) cause damage to the intestinal villi causing malabsorptive diarrhea [2]. Clinically, calves with diarrhea have higher volumes of viscous feces and often develop varying degrees of dehydration, acidosis, fever, and depression [3]. Treatment typically includes correction of hydration and acid-base balance with oral or intravenous fluids [4], antimicrobial therapy to treat and prevent secondary septicemia [5], and other ancillary treatments [6]. Calves with diarrhea also have reduced levels of activity and feed intakes [7]. These behaviors are likely related to the discomfort and inflammation associated with clinical diarrhea.

Meloxicam, a non-steroidal anti-inflammatory drug (NSAID) is a potent, selective cyclooxygenase-2 inhibitor with antipyretic, anti-inflammatory, and analgesic properties [8]. Meloxicam has been used to treat the pain and inflammation associated with a variety of medical conditions and procedures in cattle, including mastitis [9], dehorning [10], castration [11], abdominal surgery [12], and lameness [13]. In calves with mild to moderate diarrhea, researchers found that treating with a single dose of meloxicam parenterally resulted in improved feed and water intakes, higher average daily gains in bodyweight pre-weaning, and earlier weaning ages relative to untreated controls [14]. Researchers hypothesized that the addition of meloxicam ameliorated abdominal pain and systemic associated with diarrhea, reducing sickness behavior and improving appetite in treated animals.

Pharmacokinetics of meloxicam following oral and intravenous routes of administration has been well studied in healthy young and mature cattle [15] [16] [17]. Despite this, to the authors' knowledge, there is no peer-reviewed research evaluating the pharmacokinetic properties of meloxicam in diarrheic animals, specifically in milk-fed calves. Further, few studies have compared drug pharmacokinetics when meloxicam is administered in differing manners in young calves. Given the availability of oral meloxicam solutions (Meloxicam Oral Suspension, $15 \mathrm{mg} / \mathrm{ml}$, Solvet, Alberta, Canada), it is important to understand drug pharmacokinetics when delivered using a variety of methods, namely subcutaneously, oral bolus, administration in oral electrolyte solution, and administration in milk replacer at feeding.

The objective of the current study was to compare the pharmacokinetics of meloxicam in mild to moderate diarrheic milk-fed dairy calves dosed either orally (oral bolus, in electrolytes, or in milk replacer) or subcutaneously.

\section{Materials and Methods}

\subsection{Herd, Animals, Housing, and Feeding}

The current study was carried out in accordance with the recommendations of 
the Guide to Care and Use of Farm Animals in Research, Teaching and Testing set forth by the Canadian Council on Animal Care. The protocol was reviewed and approved by the Alberta Agriculture Institutional Animal Care and Use Committee (Airdrie, AB, Canada: AVL18006).

The study site was a commercial male calf rearing operation in Alberta, Canada. The study was conducted in August 2018. The operation typically buys male Holstein calves from surrounding dairy producers and assembles them at their facility. On average, they feed 10,000 calves per year. Animal sizes range between 35 and $50 \mathrm{~kg}$ at arrival to the facility. Animals were housed in individual pens for the first 8 weeks of life, then moved into group housing at weaning, where they were then transitioned to solid feed.

Animals were fed $2.6 \mathrm{~L}$ of a commercial milk replacer (24\% protein, $20 \%$ fat with $0.5 \mathrm{mg}$ decoquinate/ $\mathrm{kg}$ body weight) twice daily until weaning. In addition, all animals were provided ad lib water and solid calf starter during the pre-weaning period. Progressively larger amounts of solid feed were provided to calves in the pre-weaning period. Animals were weaned at 8 weeks of age when they are consuming in excess of $1 \mathrm{~kg}$ of solid feed per head daily.

\subsection{Case Definition}

For this study, the calf was the experimental unit of concern. Fecal consistency was scored on a 5-point scale, where score $1=$ normal consistency (formed/solid); 2 = slightly loose but stays on top of bedding (yogurt-like); 3 = maple syrup-like; 4 = watery diarrhea with some fecal matter; $5=$ severe watery diarrhea. Diarrhea was classified as fecal scores $>2$. Calf respiratory system was scored on a 5-point scale, with $1=$ normal respiration rate and effort; $2=$ slight cough is present but normal breathing; 3 = moderate cough with rapid breathing; $4=$ severe cough with rapid breathing; and $5=$ severe cough with rapid, irregular breathing. General appearance of the calf was scored on a 4-point scale, with $1=$ alert and active; 2 droopy ears and responsive; $3=$ moderately unresponsive with both head and ears drooping; 4 = unresponsive with head and ears drooping and unable to rise. A total clinical score was calculated by summing fecal, respiratory, and appearance scores together, with a maximum score of 14 indicating a calf exhibiting severe clinical signs due to diarrhea.

To be eligible for participation in the study, a pre-weaned animal with diarrhea (fecal score $>2$ ) must have had a respiratory score $<2$, an appearance score $<3$, and been able to consume their milk allotment. Animals that had previously been treated with an NSAID compound, were depressed/dull/dehydrated on physical examination, or had blood or fibrin in their feces were ineligible for enrollment in the study.

\subsection{Experimental Design}

Calves at the facility were inspected daily for general health condition by trained farm personnel. Weight was determined using a digital scale that had been tested and approved by a licensed scale certification service within the 12 months prior 
to the study. Body weight was rounded to the nearest $1 \mathrm{~kg}$. Calves that met the case definition were randomly assigned one of 4 treatments: subcutaneous injection of meloxicam (SM, $0.5 \mathrm{mg} / \mathrm{kg}$ body weight; Metacam, Boehringer Ingelheim Animal Health, Burlington, Ontario, Canada); oral bolus meloxicam (OM, 1 $\mathrm{mg} / \mathrm{kg}$ body weight; Meloxicam Oral Suspension [MOS], Solvet, Calgary, Alberta, Canada); MOS added to a feeding of oral electrolytes (EM, $1 \mathrm{mg} / \mathrm{kg}$ body weight); and MOS added to a feeding of milk replacer (MM, $1 \mathrm{mg} / \mathrm{kg}$ body weight). A total of 12 calves were enrolled ( 3 calves per treatment group). The OM group were administered their calculated dose of meloxicam via oral syringe. For those treatments relying on the calf consuming meloxicam of their own volition, research technicians were instructed to record the volume of electrolyte solution or milk replacer not consumed by the calf. Final experimental number was based on logistic and economic considerations.

Once eligibility was confirmed, all calves were weighed, and exams were performed scoring feces, respiration, and general appearance. Fecal samples were collected to identify the causative agents of diarrhea. An animal-side detection system (Bovine Enterichek, Biovet Inc, Saint-Hyacinthe, Quebec, Canada) was employed to identify the presence of rotavirus, coronavirus, E. coli K99, and/or Cryptosporidium spp. in samples. Briefly, one level measuring spoonful of feces was collected from each sample. It was then diluted in test reagent provided by the manufacturer. The feces-reagent solution was then homogenized. Test strips for each of the pathogens were submerged in the feces-reagent solution for 10 minutes, and then removed from the liquid. Two lines on the test strip indicated presence of the specific pathogen, whereas one line confirmed its absence.

Blood samples were collected via jugular venipuncture into heparinized (green top), EDTA-containing (purple top), and non-heparinized (red top) tubes. A $16 \mathrm{G}$ indwelling intravenous catheter was placed in the jugular vein and attached to an extension set. Blood was collected at timepoints of $0,1,2,4,8,12,24,48$, and 72 hours following meloxicam administration. Samples were centrifuged for 20 minutes at $200 \times \mathrm{g}$ in a temperature-controlled (approximately $5^{\circ} \mathrm{C}$ ) centrifuge. Plasma samples were then transferred into prelabelled plastic vials and stored at $-20^{\circ} \mathrm{C}$ until they were submitted for analysis. Serum samples were sent to the veterinary diagnostic laboratory for complete blood count and biochemical analysis. All farm personnel assessing animal condition and collecting samples were blinded to experimental treatment. The technician administering treatments and the statistician were not blinded to experimental treatment allocation.

\subsection{Laboratory Analysis for Meloxicam in Plasma Samples}

The diagnostic laboratory (Chinook Contract Research, Airdrie Alberta, Cana$\mathrm{da}$ ) received the samples and they were rapidly transferred to frozen storage $\left(-20^{\circ} \mathrm{C}\right)$. Storage temperature was monitored by a NIST-certified temperature-recording device. Plasma samples were analyzed with a validated 
high-performance liquid chromatography (HPLC) (Agilent 1200 HPLC, Agilent, CA, USA) procedure that was conducted using UV detection [18]. An internal standard (piroxicam) was added to the untreated plasma sample. Standard concentrations used were $0.05,0.1,0.5,1,2,3,4$, and $6 \mu \mathrm{g} / \mathrm{mL}$ respectively. Meloxicam and the internal standard were then extracted from plasma by solid-phase extraction (SPE). The SPE cartridges were connected to a vacuum manifold and conditioned with $1 \mathrm{~mL}$ methanol followed by $1 \mathrm{~mL}$ of water. The samples were passed through sorbents at a flow rate of less than $1 \mathrm{~mL} / \mathrm{min}$. The cartridges were then rinsed with $1 \mathrm{~mL}$ of $5 \%$ methanol and dried under vacuum for $2 \mathrm{~min}$. Analytes were eluted with $1.5 \mathrm{~mL}$ of methanol. The eluent was then dried under vacuum at $40^{\circ} \mathrm{C}$ for $2 \mathrm{~h}$ and the dried residue was reconstituted in $100 \mu \mathrm{L}$ of mobile phase. The reconstituted sample was vortexed for $15 \mathrm{~s}$ then centrifuged at $14,000 \times \mathrm{g}$ for $10 \mathrm{~min}$ to remove any particulate from the sample. Following centrifugation, $10 \mu \mathrm{L}$ of supernatant was injected into the HPLC system. HPLC apparatus consisted of a pump system equipped with an automatic injector and UV detector $(360 \mathrm{~nm})$. Separation was achieved using a reverse-phase column $(\mathrm{C} 18,3 \mathrm{~mm}, 125 \times 3.0 \mathrm{~mm})$ and a guard column $(\mathrm{C} 18,10 \times 30 \mathrm{~mm})$. The mobile phase consisted of a mixture of acetic acid: $1 \%$ methanol (40:60) at a flow rate of $0.4 \mathrm{~mL} / \mathrm{min}$. For these conditions, meloxicam and piroxicam were eluted at a retention time of 7.8 and $5.4 \mathrm{~min}$, respectively. Results for the method were linear over the calibration range of 10 to $1250 \mathrm{ng} / \mathrm{mL}$ as determined by use of a weighted linear regression model. Within-day and day-day precision were $<10 \%$. Accuracy ranged from $96 \%$ to $99 \%$. The validated limit of quantification (LOQ) was $10 \mathrm{ng} / \mathrm{mL}$.

\subsection{Pharmacokinetic Analysis}

Pharmacokinetic parameters were estimated for each animal using non-compartmental analysis using PKSolver, a validated Microsoft Excel add-on [19]. The maximum plasma concentration (Cmax) and time taken to reach maximum concentration (Tmax) were determined directly from the data. The area under the curve from 0 to last measurement $\left(\mathrm{AUC}_{0_{-t}}\right)$, $\mathrm{AUC}$ from 0 to infinity $\left(\mathrm{AUC}_{0-\infty}\right.$, estimated with the linear fit of the natural log using the trapezoidal rule), the meloxicam plasma half-life (T1/2), and elimination rate (ke) were subsequently calculated for each calf.

\subsection{Statistical Analysis}

All data were transcribed into a comma-separated value file (Microsoft Excel, Microsoft Corp., Redmond, Washington, USA). Subsequently, datasets were imported into a statistical analysis software for further analysis (Stata IC 14, StataCorp, College Station, Texas, USA). Descriptive statistics were generated evaluating pharmacokinetic outcomes of interest, as well as calf-level demographics, pathogens identified, and physiological parameters evaluated. Univariable linear regression models were used to study variables of interest. A liberal P-value of 
$<0.2$ was employed to identify important variables to explore in subsequent multivariable modeling. Following univariable analysis, appropriate multivariable regression models were constructed. When evaluating serum meloxicam as an outcome, a repeated measures mixed linear regression model was employed using random effects to model sampling time within calf, using a first-order autoregressive covariance structure to account for within-subject correlation over time. Model fit was assessed through the creation of standardized residuals. Residuals were plotted against predicted outcomes, and homogeneity of variance was visually assessed. Normality was graphically assessed by producing a normal Q-Q plot.

\section{Results}

A description of experimental calves stratified by treatment group is presented in Table 1. Both calf weight and average days on feed did not differ between experimental groups. Rotavirus and Cryptosporidium parvum were the only pathogens diagnosed in cases of diarrhea. Most calves had diarrhea scores $\leq 3$ and total clinical scores $\leq 4$, and there were no differences between experimental groups $(\mathrm{P}>0.05)$.

Table 1. Descriptive statistics of clinical and demographic parameters for study calves.

\begin{tabular}{|c|c|c|c|c|c|}
\hline Metric & $\mathrm{OM}^{1}$ & $\mathrm{MM}^{2}$ & $\mathrm{EM}^{3}$ & $\mathrm{SM}^{4}$ & P-Value \\
\hline Days on feed & $10(1.7)$ & $9.7(0.58)$ & $9.7(0.58)$ & $9.3(1.53)$ & 0.9 \\
\hline Body Weight $(\mathrm{kg})$ & $44.1(6.7)$ & $39.8(9.9)$ & $41.9(3.0)$ & $42.8(3.3)$ & 0.8 \\
\hline \multicolumn{6}{|c|}{ Diarrhea Pathogens (\%) } \\
\hline Crypto $^{5}$ only & 33 & 0 & 33 & 33 & \multirow{3}{*}{0.3} \\
\hline Rota $^{6}$ only & 33 & 0 & 0 & 33 & \\
\hline Crypto + Rota & 33 & 100 & 66 & 33 & \\
\hline \multicolumn{6}{|l|}{ Fecal Score } \\
\hline$\leq 3$ & 3 & 3 & 2 & 2 & \multirow{2}{*}{0.5} \\
\hline$>3$ & 0 & 0 & 1 & 1 & \\
\hline \multicolumn{6}{|l|}{ Respiration Score } \\
\hline 1 & 3 & 3 & 3 & 3 & \\
\hline$>1$ & 0 & 0 & 0 & 0 & \\
\hline \multicolumn{6}{|l|}{ Appearance Score } \\
\hline$\leq 2$ & 3 & 3 & 3 & 3 & \multirow{2}{*}{ - } \\
\hline$>2$ & 0 & 0 & 0 & 0 & \\
\hline \multicolumn{6}{|l|}{ Total Clinical Score } \\
\hline$\leq 4$ & 2 & 1 & 1 & 2 & \multirow{2}{*}{0.7} \\
\hline$>4$ & 1 & 2 & 2 & 1 & \\
\hline
\end{tabular}

${ }^{1} \mathrm{OM}=$ Oral meloxicam; ${ }^{2} \mathrm{MM}=$ Meloxicam in milk; ${ }^{3} \mathrm{EM}=$ Meloxicam in electrolytes; ${ }^{4} \mathrm{SM}=$ subcutaneous meloxicam; ${ }^{5}$ Cryptosporidium parvum; ${ }^{6}$ Rotavirus. 
After controlling for body weight at the onset of diarrhea, results of the multivariable, repeated measures model are presented in Figure 1. Plasma meloxicam levels for the SM group of calves were significantly lower than all other treatment groups starting at the 4 th hour post-treatment and continuing for the duration of the experiment (72 hours) $(\mathrm{P}<0.05)$. Calves in the MM group had significantly higher plasma meloxicam values than the $\mathrm{OM}$ and $\mathrm{ME}$ group at the 72-hour sample (Figure 1, $\mathrm{P}<0.05$ ).

After controlling for calf body weight, pharmacokinetic parameter estimates are presented in Table 2. Reliable estimates could not be made for one calf in the MM treatment group, as the plasma meloxicam levels remained constant throughout the final 3 samples. The plasma half-life was significantly longer for calves in the MM group relative to SM. Additionally, the maximal plasma concentration was approximately $2 \mathrm{ug} / \mathrm{ml}$ lower in the SM group relative to all other

Table 2. Multivariable model results comparing pharmacokinetic parameters between experimental groups.

\begin{tabular}{ccccc}
\hline \multicolumn{4}{c}{ Predicted Means (SE) } \\
\hline Metric & OM $^{1}$ & MM $^{2}$ & EM $^{3}$ & SM $^{4}$ \\
\hline Half-life $^{5}(\mathrm{~h})$ & $56.8^{\mathrm{ab}}(21.7)^{\star *}$ & $136.0^{\mathrm{b}}(26.6)$ & $85.2^{\mathrm{ab}}(21.7)$ & $36.3^{\mathrm{a}}(21.7)$ \\
$\mathrm{Cmax}^{6}$ & $4.3^{\mathrm{a}}(0.4)$ & $3.7^{\mathrm{a}}(0.4)$ & $3.9^{\mathrm{a}}(0.4)$ & $2.1^{\mathrm{b}}(0.4)$ \\
$\operatorname{Tmax}^{7}$ & $13.3^{\mathrm{a}}(4.0)$ & $10.7^{\mathrm{a}}(4.0)$ & $13.3^{\mathrm{a}}(4.0)$ & $2.7^{\mathrm{b} *}(4.0)$ \\
$\mathrm{AUC}_{0-\mathrm{t}}^{8}$ & $224.8^{\mathrm{a}}(12.6)$ & $227.4^{\mathrm{a}}(12.7)$ & $208.1^{\mathrm{a}}(12.4)$ & $95.8^{\mathrm{b}}(12.4)$ \\
$\mathrm{AUC}_{0-\infty}^{9 * *}$ & $383.4^{\mathrm{ab}}(126.8)$ & $877.8^{\mathrm{b}}(155.3)$ & $457.1^{\mathrm{ab}}(126.8)$ & $126.4^{\mathrm{a}}(126.8)$ \\
\hline
\end{tabular}

${ }^{1} \mathrm{OM}=$ Oral meloxicam; ${ }^{2} \mathrm{MM}=$ Meloxicam in milk; ${ }^{3} \mathrm{EM}=$ Meloxicam in electrolytes; ${ }^{4} \mathrm{SM}=$ subcutaneous meloxicam; ${ }^{5}$ Half-life in hours $(\mathrm{h}) ;{ }^{6}$ Maximum plasma concentration $(\mu \mathrm{g} / \mathrm{mL}) ;{ }^{7}$ Time at maximum plasma concentration (h); ${ }^{8}$ Area under the curve from 0 to last time $\left(\mathrm{h}{ }^{*} \mu \mathrm{g} / \mathrm{mL}\right) ;{ }^{9}$ Area under the curve from 0 to infinity. ${ }^{\mathrm{a}, \mathrm{b}}$ Values within rows with means of different superscripts are significantly different $(\mathrm{p}<0.05)$. ${ }^{*} \mathrm{P}$-value $=0.10$ (tendency), ${ }^{*}$ Unable to estimate pharmacokinetic parameters for one calf in the MM group. Note: body weight was a significant covariate in the $\mathrm{Cmax}$ and $\mathrm{AUC}_{0-\mathrm{t}}$ linear models.

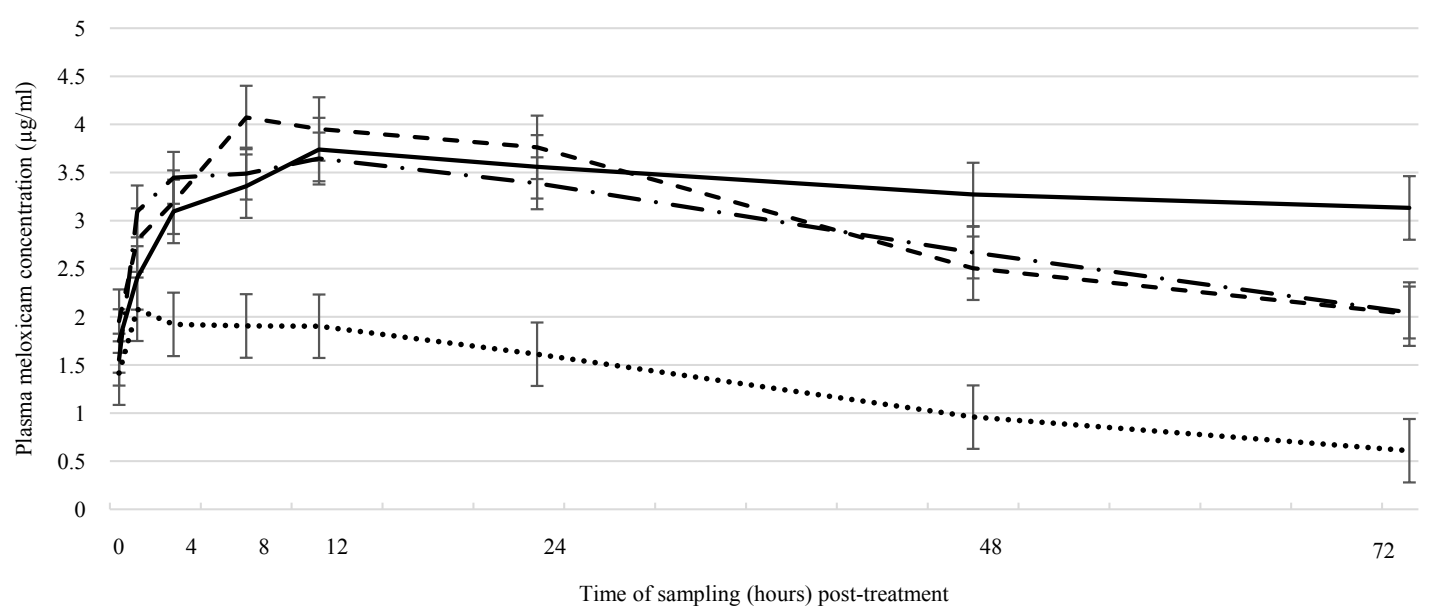

Figure 1. Linear marginal predictions ( \pm standard error) of plasma meloxicam levels between meloxicam directly administered orally (- - -), meloxicam administered in milk replacer (-), meloxicam administered in electrolyte feedings (-. - -), and meloxicam administered subcutaneously (.....) in diarrheic study calves. 
groups. There was a tendency $(\mathrm{P}=0.10)$ for SM calves to have lower Tmax values compared with all other groups. Finally, the $\mathrm{AUC}_{0-\mathrm{t}}$ was lower in the $\mathrm{SM}$ group when compared to the MM group.

\section{Discussion}

To the authors' knowledge, this is the first study to evaluate the pharmacokinetic properties of meloxicam in calves experiencing mild to moderate diarrhea. Previous research has found that diarrheic calves that received meloxicam started eating solid feed sooner, were weaned earlier, and had a higher rate of weight gain relative to calves treated with a placebo [14]. Very little pharmacokinetic research has been conducted in sick animals, yet their physiological state may alter drug metabolism relative to healthy animals [20]. This may not only affect drug action; it could also impact drug residues and meat withdrawal times [21]. Given the increased use and availability of NSAIDs, it is important to understand how these drugs behave in sick or compromised animals.

Most of the published pharmacological literature studying meloxicam has been carried out in ruminating cattle. One study [17] looked at the pharmacokinetics of orally dosing older, weaned calves at $1 \mathrm{mg} / \mathrm{kg}$ of meloxicam in tabular form (a SM group was also used). At the oral dose used in this study, animals in the MM, OM, and EM groups had substantially higher values for AUC, Tmax, and half-life relative to ruminant calves treated with oral meloxicam tablets [17]. When comparing the SM results from the current study to [17], SM calves differed in Cmax (2.1 vs $3.1 \mu \mathrm{g} / \mathrm{ml}$ ) and $\mathrm{Tmax}$ (2.7 vs 11.6), but the $\mathrm{AUC}_{0-\infty}(126.4$ vs 164.4 ) and half-lives (36.3 vs $27.5 \mathrm{hr}$ ) were similar despite differing routes of administration, stage of rumen development, and dosage levels.

Previous research has studied the effects of feeding oral meloxicam in milk replacer to pre-ruminant calves [15]. It should be noted that [15] used an oral meloxicam dose of $0.5 \mathrm{mg} / \mathrm{kg}$ body weight, versus the higher oral dose of 1 $\mathrm{mg} / \mathrm{kg}$ used in the current study. Interestingly, the current study observed numerically higher (though not statistically different) values for half-life and $\mathrm{AUC}_{0-\infty}$ when meloxicam was fed with milk versus oral gavage or electrolyte feeding. Previous research observed an inverse relationship with $\mathrm{AUC}_{0-\infty}$ and half-life, with calves fed via gavage having significantly higher values for these parameters [15]. Given dose differences between studies, it is unsurprising that calves in the current study had substantially higher values for AUC (double to triple), Cmax (double), and half-life (double) relative to [15]. However, the SM group in the current study had similar pharmacokinetic values to that of the oral gavage group in [15] for AUC (126.4 (h* $\mu \mathrm{g} / \mathrm{mL}$ vs $\left.151 \mathrm{~h}{ }^{*} \mu \mathrm{g} / \mathrm{mL}\right)$, half-life (36.3 h vs $40 \mathrm{~h}$ ), and Cmax $(2.1 \mu \mathrm{g} / \mathrm{mL}$ vs $2.2 \mu \mathrm{g} / \mathrm{mL})$.

There are several reasons why the pharmacokinetic values of orally dosed meloxicam in the present study may differ from previous research. First, the oral dose used in the current study ( $1 \mathrm{mg} / \mathrm{kg}$ body weight, label dose for calves) was twice that of previous research $(0.5 \mathrm{mg} / \mathrm{kg}$ body weight). This renders the value 
of any direct comparisons tenable at best. Further, subjects in the current study were experiencing a clinical episode of diarrhea, whereas previous studies enrolled healthy test subjects for pharmacokinetic analysis [15]. Though based on the initial biochemical analysis none of the animals in the current study were severely dehydrated, moderate levels of dehydration associated with diarrhea may have impaired kidney and liver function, ultimately prolonging systemic meloxicam levels [22]. Furthermore, previous research included calves between 18 and 28 days of age, whereas calves in the current study were less than 2 weeks of age. Finally, the oral meloxicam used in the current study was in liquid suspension formulation compared with previous research that employed tabular meloxicam. Relative to tablet formulations, liquid NSAIDs may offer faster absorption and earlier onset of action [23].

One important finding of this study is the prolonged elimination associated with administering meloxicam in milk. Meloxicam is a hydrophobic molecule, and when dosed orally in milk, meloxicam likely interacts with milk fat and protein components [24]. We hypothesize that these characteristics are therefore likely to affect absorption and tissue distribution, leading to a prolonged elimination phase relative to other treatment groups (OM, EM, SM). Indeed, the prolonged systemic meloxicam levels associated with oral administration should be considered when treating dehydrated animals. NSAID drugs can lead to deleterious side-effects, including gastric ulceration and nephrotoxicity [25]. Dehydrated animals already have altered renal perfusion, and the addition of an NSAID may lead to increased risk for renal damage [26]. Oral meloxicam has been shown to be safe at $1.0 \mathrm{mg} / \mathrm{kg}$ body weight in safety studies conducted for registration. The unique safety of the molecule can be attributed to the COX 2 properties, which protect animals from gastric, hepatic, and renal toxicities [8] [15] [17] [25]. Practices such as avoiding meloxicam administration in milk, using parenteral dosage formulations, or avoiding treatment altogether may be advisable for severely compromised animals. Although no adverse side-effects were noted in study animals, veterinarians and producers should exercise caution when administering any NSAID to compromised animals.

There are a few limitations that must be mentioned when interpreting the findings of the study. First, because differing doses of meloxicam were used for oral and subcutaneous treatment groups $(1 \mathrm{mg} / \mathrm{kg}$ body weight versus $0.5 \mathrm{mg} / \mathrm{kg}$ body weight), a direct comparison of pharmacokinetic parameters is not possible. Second, oral dosing of meloxicam has proven to yield variable pharmacokinetic results [15]. Blood meloxicam concentrations, especially in the MM group, were variable around the elimination phase. Lastly, pharmacokinetic parameters could not be calculated for one calf in the MM group. The meloxicam elimination phase was quite prolonged for this calf, precluding an accurate estimation of pharmacokinetic parameters for this calf.

\section{Conclusion}

The administration of meloxicam at label doses, either orally or subcutaneously, 
results in therapeutic plasma levels in calves. Oral meloxicam administered in milk or electrolyte solutions results in similar pharmacokinetic outcomes when compared to calves dosed via direct oral bolus. Caution should be exercised when administering meloxicam, particularly orally and in association with a milk meal, as this may result in prolonged systemic meloxicam levels. This is especially true for meloxicam administered in milk. The clinical significance of these findings needs further investigation.

\section{Acknowledgements}

The authors would like to thank all farm personnel involved in the study.

\section{Author Contributions}

This research was funded by Solvet Inc, the manufacturer of Meloxicam Oral Suspension. Solvet financially supported the conduct, data analysis, and reporting of the study.

\section{Funding}

The following outlines author contributions to each stage of the clinical study: conceptualization, $\mathrm{MO}$ and $\mathrm{DN}$; methodology, $\mathrm{MO}$ and $\mathrm{DN}$; formal analysis, DS; investigation, $\mathrm{DN}$; data curation, $\mathrm{MO}$ and $\mathrm{DN}$; writing-original draft preparation, DS and SR; writing-review and editing, MO, DS, SR; supervision, MO; project administration, $\mathrm{MO}$; funding acquisition, $\mathrm{MO}$.

\section{Conflicts of Interest}

$\mathrm{MO}$ and DN are salaried employees of Solvet Inc. The authors DS and SR received funding from Solvet Inc. for data analysis and manuscript preparation. The funders had no role in the analysis, interpretation of data, and preparation of the draft manuscript.

\section{References}

[1] United States Department of Agriculture (2014) Health and Management Practices on U.S. Dairy Operations, 2014. Fort Collins, CO.

https://www.aphis.usda.gov/animal_health/nahms/dairy/downloads/dairy14/Dairy1 4_dr_PartIII.pdf

[2] Foster, D.M. and Smith, G.W. (2009) Pathophysiology of Diarrhea in Calves. Veterinary Clinics of North America: Food Animal Practice, 25, 13-36. http://www.sciencedirect.com/science/article/pii/S0749072008000911 https://doi.org/10.1016/j.cvfa.2008.10.013

[3] Smith, G.W. (2009) Treatment of Calf Diarrhea: Oral Fluid Therapy. Veterinary Clinics of North America: Food Animal Practice, 25, 55-72. http://www.sciencedirect.com/science/article/pii/S0749072008000972 https://doi.org/10.1016/j.cvfa.2008.10.006

[4] Smith, G.W. and Berchtold, J. (2014) Fluid Therapy in Calves. Veterinary Clinics of North America: Food Animal Practice, 30, 409-427.

http://www.ncbi.nlm.nih.gov/pubmed/24980729 
https://doi.org/10.1016/j.cvfa.2014.04.002

[5] Constable, P.D. (2004) Antimicrobial Use in the Treatment of Calf Diarrhea. Journal of Veterinary Internal Medicine, 18, 8-17. https://doi.org/10.1111/j.1939-1676.2004.tb00129.x

[6] Constable, P.D. (2009) Treatment of Calf Diarrhea: Antimicrobial and Ancillary Treatments. Veterinary Clinics of North America: Food Animal Practice, 25, 101-120. https://doi.org/10.1016/j.cvfa.2008.10.012

[7] Sutherland, M.A., Lowe, G.L., Huddart, F.J., Waas, J.R. and Stewart, M. (2018) Measurement of Dairy Calf Behavior Prior to Onset of Clinical Disease and in Response to Disbudding Using Automated Calf Feeders and Accelerometers. Journal of Dairy Science, 101, 8208-8216. https://doi.org/10.3168/jds.2017-14207

[8] Davies, N.M. and Skjodt, N.M. (1999) Clinical Pharmacokinetics of Meloxicam: A Cyclooxygenase-2 Preferential Nonsteroidal Anti-Inflammatory Drug. Clinical Pharmacokinetics, 36, 115-126. https://doi.org/10.2165/00003088-199936020-00003

[9] Fitzpatrick, C.E., Chapinal, N., Petersson-Wolfe, C.S., DeVries, T.J., Kelton, D.F., Duffield, T.F. and Leslie, K.E. (2013) The Effect of Meloxicam on Pain Sensitivity, Rumination Time, and Clinical Signs in Dairy Cows with Endotoxin-Induced Clinical Mastitis. Journal of Dairy Science, 96, 2847-2856. https://doi.org/10.3168/jds.2012-5855

[10] Heinrich, A., Duffield, T.F., Lissemore, K.D. and Millman, S.T. (2010) The Effect of Meloxicam on Behavior and Pain Sensitivity of Dairy Calves Following Cautery Dehorning with a Local Anesthetic. Journal of Dairy Science, 93, 2450-2457. http://linkinghub.elsevier.com/retrieve/pii/S0022030210002481 https://doi.org/10.3168/jds.2009-2813

[11] Olson, M.E., Ralston, B., Burwash, L., Matheson-Bird, H. and Allan, N.D. (2016) Efficacy of Oral Meloxicam Suspension for Prevention of Pain and Inflammation Following Band and Surgical Castration in Calves. BMC Veterinary Research, 12, 102. https://doi.org/10.1186/s12917-016-0735-3

[12] Newby, N.C., Tucker, C.B., Pearl, D.L., LeBlanc, S.J., Leslie, K.E., von Keyserlingk, M.A.G. and Duffield, T.D. (2013) Short Communication: A Comparison of 2 Nonsteroidal Antiinflammatory Drugs Following the First Stage of a 2-Stage Fistulation Surgery in Dry Dairy Cows. Journal of Dairy Science, 96, 6514-6519. https://doi.org/10.3168/jds.2013-6579

[13] Nagel, D., Wieringa, R., Ireland, J. and Olson, M.E. (2016) The Use of Meloxicam Oral Suspension to Treat Musculoskeletal Lameness in Cattle. Veterinary Medicine Research and Reports, 7, 149-155. https://doi.org/10.2147/VMRR.S112200

[14] Todd, C.G., Millman, S.T., McKnight, D.R., Duffield, T.F. and Leslie, K.E. (2010) Nonsteroidal Anti-Inflammatory Drug Therapy for Neonatal Calf Diarrhea Complex: Effects on Calf Performance. Journal of Animal Science, 88, 2019-2028. https://doi.org/10.2527/jas.2009-2340

[15] Mosher, R.A., Coetzee, J.F., Cull, C.A., Gehring, R. and Kukanich, B. (2011) Pharmacokinetics of Oral Meloxicam in Ruminant and Preruminant Calves. Journal of Veterinary Pharmacology and Therapeutics, 35, 373-381. https://doi.org/10.1111/j.1365-2885.2011.01331.x

[16] Coetzee, J.F., Mosher, R.A., Kohake, L.E., Cull, C.A., Kelly, L.L., Mueting, S.L. and KuKanich, B. (2011) Pharmacokinetics of Oral Gabapentin Alone or Co-Administered with Meloxicam in Ruminant Beef Calves. Veterinary Journal, 190, 98-102. https://doi.org/10.1016/j.tvjl.2010.08.008

[17] Coetzee, J.F., Kukanich, B., Mosher, R. and Allen, P.S. (2009) Pharmacokinetics of 
Intravenous and Oral Meloxicam in Ruminant Calves. Veterinary Therapeutics, 10, E1-E8.

[18] Shock, D., Roche, S. and Olson, M.E. (2019) A Comparative Pharmacokinetic Analysis of Oral and Subcutaneous Meloxicam Administered to Postpartum Dairy Cows. Veterinary Science, 6, 73. https://doi.org/10.3390/vetsci6030073

[19] Zhang, Y., Huo, M., Zhou, J. and Xie, S. (2010) PKSolver: An Add-in Program for Pharmacokinetic and Pharmacodynamic Data Analysis in Microsoft Excel. Computer Methods Programs in Biomedicine, 99, 306-314. https://doi.org/10.1016/j.cmpb.2010.01.007

[20] Gorden, P.J., Kleinhenz, M.D., Wulf, L.W., KuKanich, B., Lee, C.J., Wang, C. and Coetzee, J.F. (2016) Altered Plasma Pharmacokinetics of Ceftiofur Hydrochloride in Cows Affected with Severe Clinical Mastitis. Journal of Dairy Science, 99, 505-514. https://doi.org/10.3168/jds.2015-10239

[21] Gorden, P.J., Ydstie, J.A., Kleinhenz, M.D., Brick, T.A., Smith, J.S., Griffith, R.W., Wulf, L.W., Rajewski, S.M., Zhang, M., Sidhu, P.K., Mochel, J.P. and Coetzee, J.F. (2018) Comparative Plasma and Interstitial Fluid Pharmacokinetics and Tissue Residues of Ceftiofur Crystalline-Free Acid in Cattle with Induced Coliform Mastitis. Journal of Veterinary Pharmacology and Therapeutics, 41, 848-860. https://doi.org/10.1111/jvp.12688

[22] Lee, J.H., Oh, J.M. and Lee, M.G. (2008) Effects of Water Deprivation on Drug Pharmacokinetics: Correlation between Drug Metabolism and Hepatic CYP Isozymes. Archives of Pharmacalogical Research, 31, 951-964. https://doi.org/10.1007/s12272-001-1269-3

[23] Al Lawati, H. and Jamali, F. (2016) Onset of Action and Efficacy of Ibuprofen Liquigel as Compared to Solid Tablets: A Systematic Review and Meta-Analysis. Journal of Pharmacy and Pharmaceutical Science, 19, 301-311. https://doi.org/10.18433/J3B897

[24] Cheema, M., Hristov, A.N. and Harte, F.M. (2017) The Binding of Orally Dosed Hydrophobic Active Pharmaceutical Ingredients to Casein Micelles in Milk. Journal of Dairy Science, 100, 8670-8679. https://doi.org/10.3168/jds.2017-12631

[25] Brune, K. and Patrignani, P. (2015) New Insights into the Use of Currently Available Non-Steroidal Anti-Inflammatory Drugs. Journal of Pain Research, 8, 105-118. https://doi.org/10.2147/JPR.S75160

[26] John, C.M., Shukla, R. and Jones, C.A. (2007) Using NSAID in Volume Depleted Children Can Precipitate Acute Renal Failure. Archives of Disease in Childhood, 92, 524-526. https://doi.org/10.1136/adc.2006.103564 